\title{
Harmonic Reduction in Space Vector PWM Controlled Diode Clamped Multilevel Inverter for Motor drives
}

\author{
P.S Anish \\ P. S P.G Scholar, Jeppiaar Engineering College, Chennai, Tamilnadu, India. \\ T.Arun Srinivas \\ Assistant Professor, Jeppiaar Engineering College, Chennai, Tamilnadu, India. \\ Dr.M.Sasikumar \\ Professor, Jeppiaar Engineering College, Chennai, Tamilnadu, India.
}

\begin{abstract}
:
This paper describes a transformer less medium voltage adjustable-speed induction motor drive consisting of two five-level diode-clamped converters connected back-to-back. It deals mainly with the voltage balancing problem that occurs when split dc capacitors are used. The switching methods by which this problem can be reduced is being described in this work. Space vector PWM is used ahead of multi carrier pulse width modulation. The harmonic values of voltage and current waveforms of the induction motor output were reduced by using the space vector PWM switching method.
\end{abstract}

Keywords:- Medium-voltage drives, multilevel inverters, Space vector modulation, voltage balancing.

\section{INTRODUCTION}

In a medium voltage drive system for driving an AC motor the method used was to use a step down transformer in the input side. This was the case when power electronic devices were of less power handling capacity. But as the technology advanced to high rated power electronic devices, the use of transformer came in a spot of bother. If the transformer is avoided from the design, losses can be reduced to a large extend. Thus the innovation of new high rated power electronic devices led to the concept of transformer less medium voltage drives. For controlling an $\mathrm{AC}$ motor, the method employed is a combination of rectifier and inverter. The converter topology used is a Voltage Source Converter (VSC). In a VSC, even if high rated semiconductor devices are used, the rating may not be sufficient to withstand the high voltage from the input. This can be avoided by using multilevel topology in both the rectifier and the inverter section. The first method was to use the offset voltage injection so that the capacitor voltage can be balanced[6]. But this method gives a notable delay in making the capacitors balanced. Another method is to use more sophisticated switching methods. This was done by Pulse Width Modulation (PWM) techniques. Multicarrier PWM can give more stability to capacitor voltage[2]. The work includes the use of Space Vector Modulation technique for the proper switching of the semiconductor devices so that voltage balancing can be achieved easily and rapidly. The harmonic levels are compared and the use of this method is justified using MATLAB / SIMULINK results.

\section{DESIGN CONCEPT OF THE TRANSFORMERLESS MOTOR DRIVE SYSTEM}

\section{A. Five-Level Diode-Clamped PWM Rectifier and Inverter}

The prototype of the $11 \mathrm{kV}$ industrial application is the main purpose of this paper. For experiment sake the rating is reduced to $230 \mathrm{~V}$ from the $\mathrm{kV}$ range[4]. The input is directly given to the multilevel rectifier section. The need for the multilevel in the input side is to reduce the input current ripple in the supply. If a normal multi pulse rectifier is used for removing the harmonics, two phase shift transformers have to be used. This again increases the cost and weight already reduced by removing the input transformer.

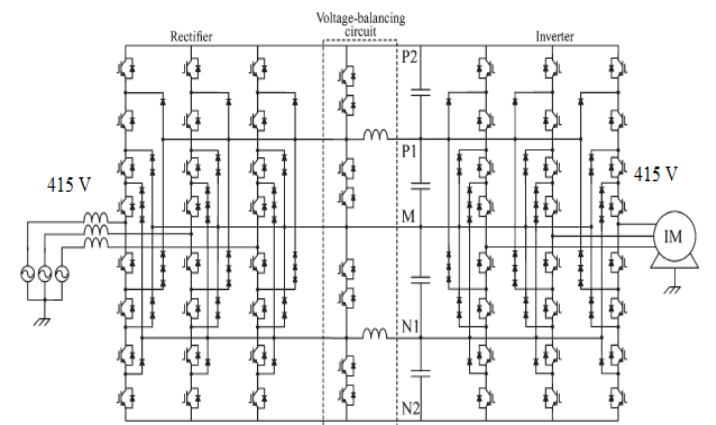




\section{P.S Anish, T.Arun Srinivas, Dr.M.Sasikumar / IOSR Journal of Engineering (IOSRJEN) www.iosrjen.org \\ ISSN : 2250-3021}

Vol. 2 Issue 1, Jan.2012, pp. 170-174

Fig 1.back to back connection of diode clamped converters with voltage balancing circuit

The weight can be reduced to a large extend. The weight of the transformer and the inverter rectifier combination is about $5000 \mathrm{~kg}$ and the transformerless system can be designed with $2000 \mathrm{~kg}$ in the industrial applications. Hence the proposed method is cost efficient. Again the multilevel inverter section used here is five level. Also the switching control is easy when using the same configuration[6].

\section{B. Voltage-Balancing Control of the Four Split DC Capacitors}

The main draw back in using dc capacitors for multilevel inverter operation is the voltage imbalance in the capacitor voltages. The four series-connected $\mathrm{dc}$ capacitors sitting between the rectifier and the inverter has the following five node points in the common dc link: the outer positive point $\mathrm{P} 2$, the inner positive point $\mathrm{P} 1$, the midpoint $\mathrm{M}$, the inner negative point $\mathrm{N} 1$, and the outer negative point $\mathrm{N} 2$, as shown in Fig. 1. Whenever the motor is operated either in powering or regenerative mode, an amount of dc current would flow into, or out of, the two inner points P1 and N1. This brings voltage imbalance to the four capacitors unless special care was taken of voltage balancing[5].

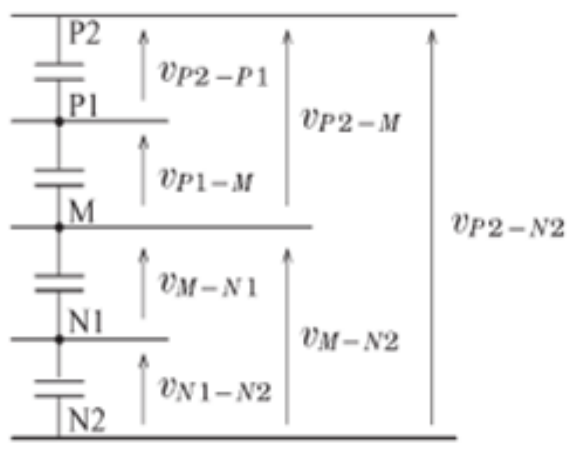

Fig. 2 DC-link voltage and split dc-capacitor voltages.

Existing solutions to the voltage imbalance inherent in the motor drive system can be classified into the following two groups: one is based on sophisticated switching control [2] and the other is based on additional hardware installation [2]. The former is more preferable in cost than the second one. The authors of [1] have proposed a practical switching-angle control method for staircase modulation or the so-called that is designed, constructed, and tested in this paper. Fig. 2 shows the dc-link voltage and the individual split dccapacitor voltages.

\section{DC LINK VOLTAGE CONTROL}

The DC link voltage in the system of discussion is the dc voltage obtained from the rectifier section. This DC voltage is supposed to be aligned itself in such a way that the voltage level across each of the dc capacitors should be the same. When the load used is having no feedback signals this condition is well met. But in the proposed system, the load used is an induction motor[7]. The back emf that is fed back to the system will cause the weak nodes of the dc link to be discharged to zero. Discharge of the dc link capacitor causes the levels of the multilevel inverter to be reduced to three whatever be the design. This can be avoided by using the average current control in the nodes. The voltage in a node is directly related to the average current flowing through the node. The average current of each node is directly related to the $\cos \beta, \cos$ $\alpha 1$ and $\cos \alpha 2$. Here

$\cos \beta$ - power factor

$\alpha 1$ - firing angle of the rectifier section

$\alpha 2$ - firing angle of the inverter section

The relation is as follows:

Let the average currents be Iavg1 and I avg2.

$$
\mathrm{I}_{\mathrm{avg} 1}=\left(\mathrm{I}_{\max } / \pi\right) \cos \beta \cos \alpha^{2}
$$

Similarly the average current of second node

$$
\mathrm{I}_{\mathrm{avg} 2}=\left(\mathrm{I}_{\max } / \pi\right) \cos \beta\left(\cos \alpha_{1}-\cos \alpha_{2}\right)(2)
$$

Thus the average current and hence the dc link voltage can be controlled by controlling the firing angle. The firing angle control can be done by controlling the switching frequency. This can be done by various PWM techniques and the technique used in this work is Space Vector PWM.

\section{SPACE VECTOR MODULATION}

This project instigates four space vector modulation algorithms - conventional with active vectors placed in the middle of the half-cycle of the carrier and the $30^{\circ}$, $60^{\circ}$, and $120^{\circ}$ discontinuous modulation algorithms. Theory tells us to expect the conventional SVM to outperform the discontinuous modulation algorithms with respect to unwanted harmonic content and ripple. One may question the use of discontinuous modulation when faced with this fact. The reason to use discontinuous modulation is to decrease the switching losses through the transistors by periodically clamping one of the three phases to a rail to produce a zero 


\section{P.S Anish, T.Arun Srinivas, Dr.M.Sasikumar / IOSR Journal of Engineering (IOSRJEN) www.iosrjen.org \\ ISSN : 2250-3021}

Vol. 2 Issue 1, Jan.2012, pp. 170-174

vector. The decrease in switching losses associated with discontinuous modulation allows the system to utilize a higher carrier / switching frequency. However, this analysis only uses one carrier frequency, $f_{c}=15 \mathrm{kHz}$. The carrier frequency governs the period in which modulation / switching of the inverter gates occurs. We want the amplitude of our stator voltage, $V$, to be $460 * \operatorname{sqrt}(2 / 3) \mathrm{V}_{\ln }$ on each phase for rated operation. This means by virtue of the inverter circuit and space vector modulation theory that the DC input to the

$$
V_{\text {in }}=V_{s} \frac{3}{2} \frac{1}{\sin (\pi / 3)}
$$

inverter must be

\section{SIMULATION RESULTS AND DISCUSSION}

The output of the motor is adjusted by designing the space vector modulation. The harmonic values are as follows.

\begin{tabular}{|c|l|l|l|l|l|l|}
\hline Order & $2^{\text {nd }}$ & 3rd & 4th & 5th & 6th & 7th \\
\hline$\%$ & 0.54 & 0.16 & 0.07 & 0.67 & 0.11 & 0.19 \\
\hline
\end{tabular}

Table 1. THD values

The simulated circuit is given below. The load used is a $3 \mathrm{hp} 200 \mathrm{~V}$ induction motor. The capacitor voltages were measured and found to be balanced. Each capacitor gives an voltage of $100 \mathrm{~V}$ each. The output voltage and current were measured. The motor load connected was an induction motor. Since the experiment is to design a prototype, the motor used is of low power rating.

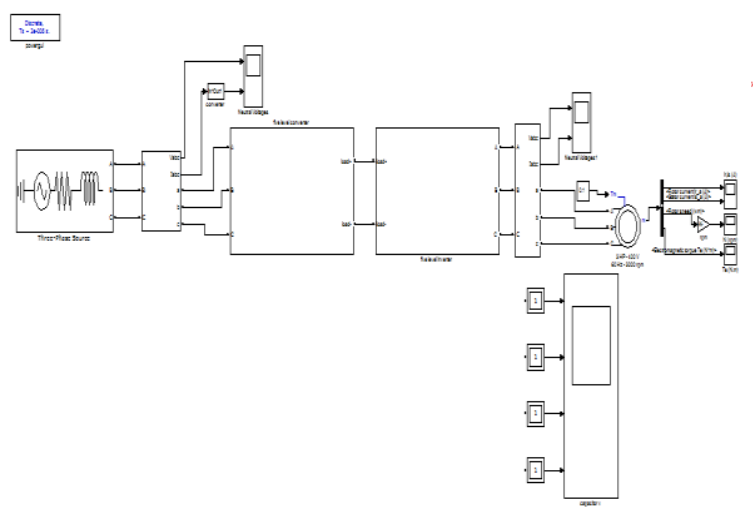

Fig 3. Simulated circuit
The harmonic value was reduced when the space vector modulation was used. The motor current harmonic was $3.9 \%$ which is under the acceptable range.

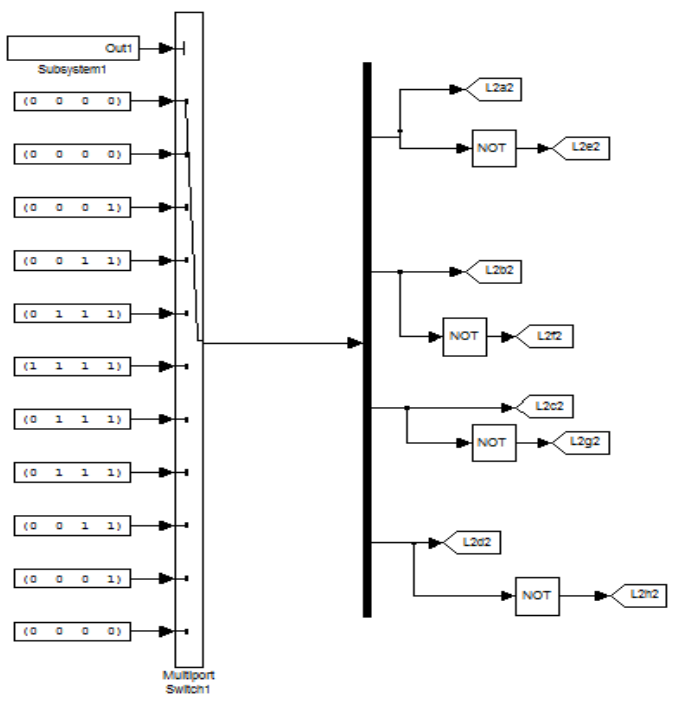

Fig 4. Space vector PWM implementation

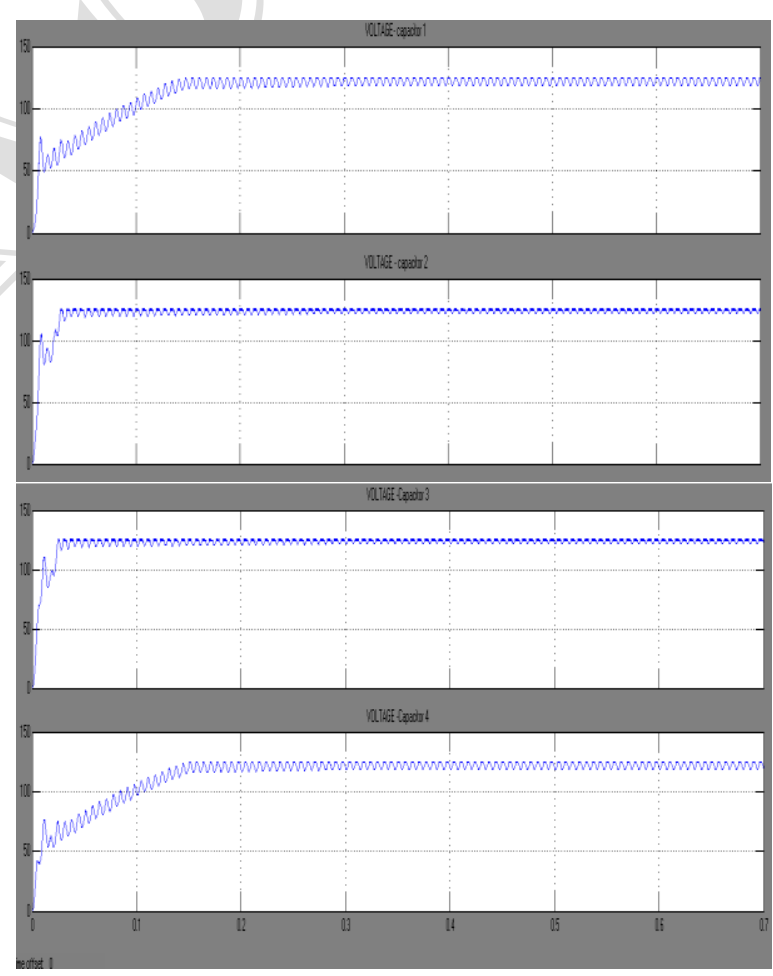

Fig 5. Capacitor voltages 


\section{P.S Anish, T.Arun Srinivas, Dr.M.Sasikumar / IOSR Journal of Engineering (IOSRJEN) www.iosrjen.org \\ ISSN : 2250-3021}

Vol. 2 Issue 1, Jan.2012, pp. 170-174

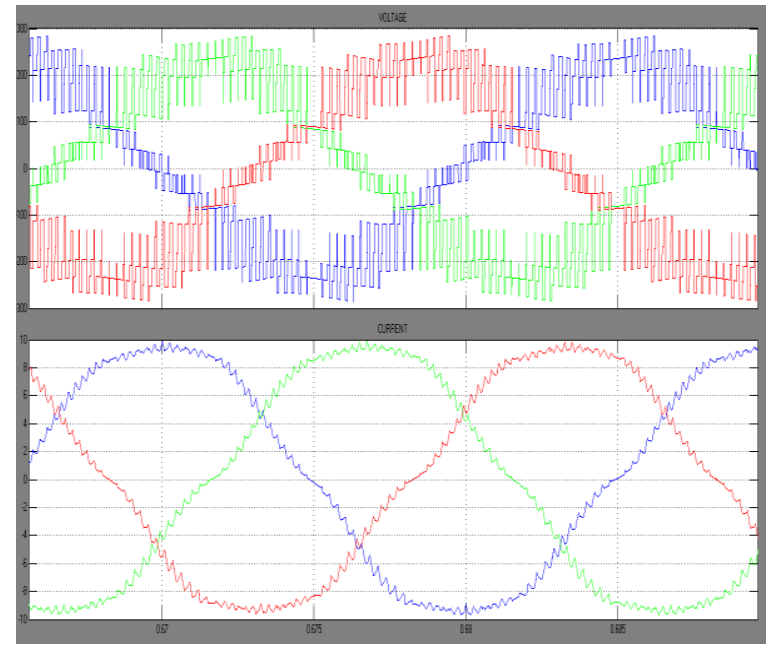

Fig 6. Output voltage and current

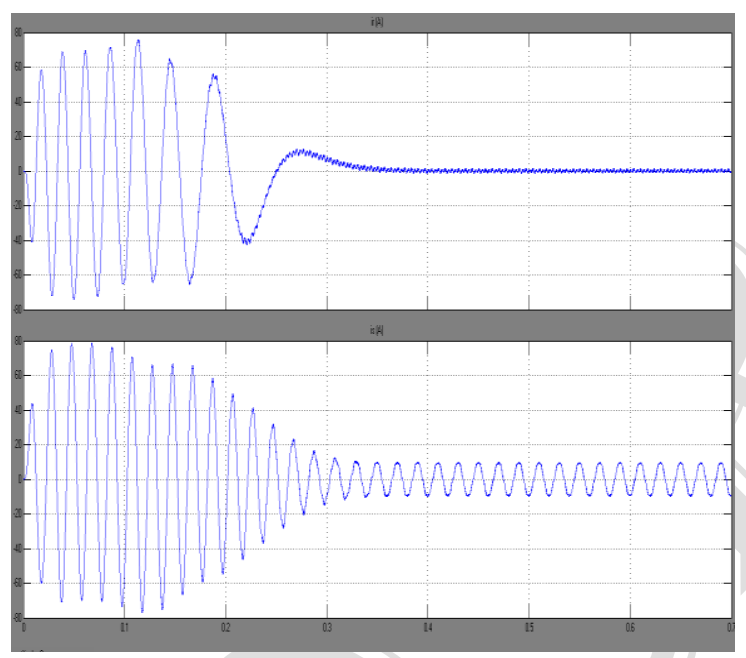

Fig 7. Stator and rotor current

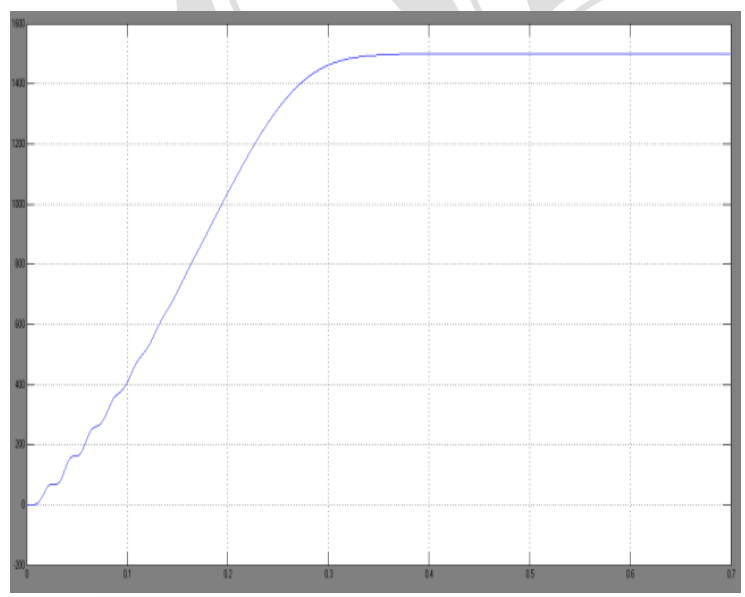

Fig 8. Rotor speed

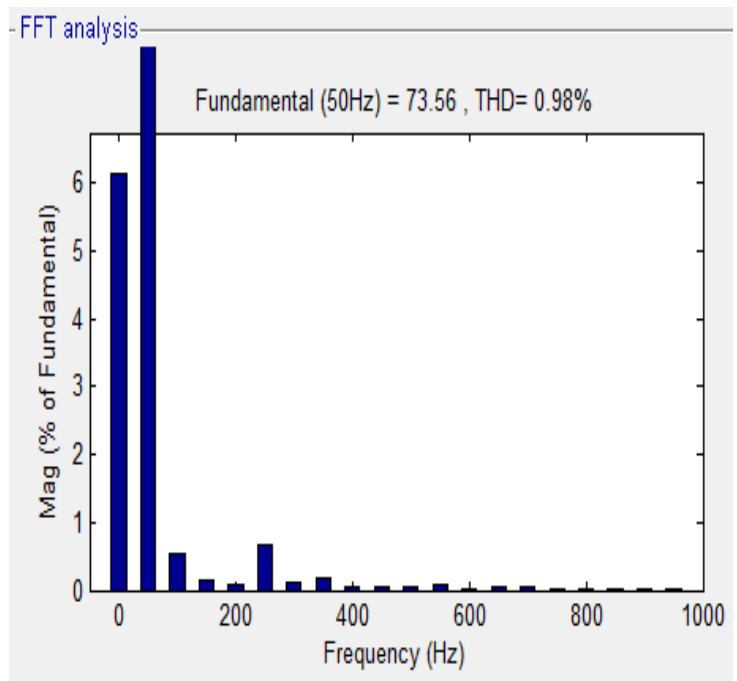

Fig 9. Output THD analysis

The THD value obtained from the rotor output is 0.98 $\%$ which is well below the accepted level. The listed values are given in table 1 . The rotor speed is set at $1500 \mathrm{rpm}$. This can be varied by varying the switching frequency. By increasing the firing angle, the voltage can be reduced and hence the speed can also be reduced. Thus by this method the motor can be made to work both in the fixed speed as well as the variable speed.

\section{CONCLUSION}

This paper deals with the various techniques used for the voltage balancing in the capacitors used in diode clamped inverters. The efficient method is to use proper modulation technique rather than going for external hardware setups. While using the space vector modulation the output THD value is $0.98 \%$. Three phase simulation is done in this paper. Three phase simulation output is also shown. The voltage balancing problem in the inverter section is rectified using the space vector PWM method. 


\section{P.S Anish, T.Arun Srinivas, Dr.M.Sasikumar / IOSR Journal of Engineering (IOSRJEN) www.iosrjen.org \\ ISSN : 2250-3021}

Vol. 2 Issue 1, Jan.2012, pp. 170-174

\section{REFERENCES}

[1] A. Nabae, I. Takahashi, and H. Akagi, "A new neutral-point-clamped PWM inverter," IEEE Trans. Ind. Appl., vol. IA-17, no. 5, pp. 518523,Sep. 1981.

[2] J. S. Lai and F. Z. Peng, "Multilevel converters-A new breed of power converters," IEEE Trans. Ind. Appl., vol. 32, no. 3, pp. 506-517,May/Jun. 1996.

[3] J.M. Erdman, R. J. Kerkman, D.W. Schlegel, and G. L. Skibinski, "Effect of PWM inverters on ac motor bearing current shaft voltage," IEEE Trans Ind. Appl., vol. 32, no. 2, pp. 250-259, Mar./Apr. 1996.

[4] B. Wu and F. DeWinter, "Voltage stress on induction motors in medium voltage (2300-6900V) PWM GTO CSI drives," IEEE Trans.Power Electron., vol. 12, no. 2, pp. 213-220, Mar. 1997.

[5] P. W. Hammond, "A new approach to enhance power quality for mediumvoltage AC drives," IEEE Trans. Ind. Appl., vol. 33, no. 1, pp. 202208,Jan./Feb. 1997.

[6] E. Cengelci, S. U. Sulistijo, B. O. Woo, R. Teodrescu, and F. Blaabjerg,"A new mediumvoltage PWM inverter topology for adjustablespeed drives," IEEE Trans. Ind. Appl., vol. 35, no. 3, pp. 628-637,May/Jun. 1999.

[7] M. Rastogi, P. W. Hammond, and R. H. Osman, "High performance, high reliability medium voltage drives," in Proc. IEEE Power Electron. DriveSyst. Conf., 2001, vol. 1, pp. 259-264.

\section{ACKNOWLEDGEMENT}

P.S Anish is currently pursuing the

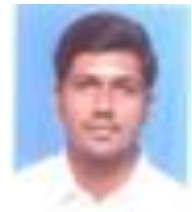
M.E Degree from Jeppiaar Engineering College, Anna University, Chennai, India. He received his B.Tech degree in Electronics and Communication Engineering in 2009 from Mar Baselios College of Engineering and Technology, Kerala University, India in 2009. His current research interests include Induction Motor Drives, Multi level inverter and Z-Source Converters.

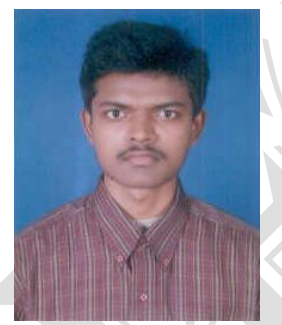

T.Arun Srinivas is currently working as an Assistant Professor in Electrical and Electronics Engineering Department, Jeppiaar Engineering College of Engineering, Chennai, India.

$\mathrm{He}$ received his B.E. degree in Electrical \& Electronics Engineering from Karunya University, Coimbatore, India and the M.E. degree in Power Electronics and Drives from Anna University, Chennai, India. He is also a Research Scholar in Anna University, Chennai. His current research interests include Power Quality, Multi level inverter and Matrix Converters.

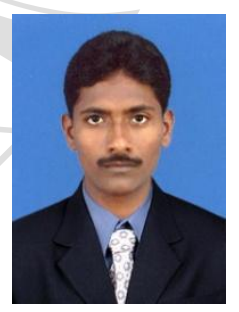

Dr.M.Sasikumar was born in tamilnadu, India on June 17, 1977. $\mathrm{He}$ received the B.E degree in electrical and electronics engineering from K.S.Rangasamy College of Technology,Madras University, India in 1999, and the M.Tech degree in power electronics from VIT University, in 2006. He has obtained his Ph.d. degree from Sathyabama university, Chennai, tamilnadu, India. Currently, he is working as a Professor in Jeppiaar Engineering College, Anna University, Chennai. He has published over 30 technical papers in National and International Conferences /proceedings / journals. 